\title{
Electronics and the Technology Gap-the Case of Numerically Controlled Machine Tools
}

Staffan Jacobsson

\section{Introduction*}

There are two facts which must be confronted by a social scientist with an interest in capital goods and the developing countries. The first is the emphasis that some developing countries put on the growth of an indigenous capital goods sector. India, Brazil, and the Republic of South Korea are particularly notable but Argentina and Mexico should not be overlooked. The second fact is the trend towards an automated production system in the engineering sector in the developed countries. With the development of microelectronics, the concept of the fully automated factory in branches characterised by small batch production has finally turned out to be feasible. Whilst there are only a handful of partially automated factories in operation today, the diffusion of individual components that will make up such a system is well under way. This applies not only to numerically controlled machine tools but also to robots and automated material handling systems, as well as computer aided design systems. Whilst the integration of these elements has not on the whole been carried out yet, the diffusion of each element on its own may have significant effects on productivity and therefore on comparative advantage in the engineering sector.

This article, which is based upon research in Sweden and Argentina, addresses one particular element in automated production-numerically controlled machine tools (NCMTs). First, I will attempt to analyse the direction of technical change in terms of any factor saving bias. In other words, has the electronification of NCMTs produced a technology which is more appropriate to the developed countries or to the developing countries? Second, I will try to analyse the impact which this technological development may have on the comparative advantage of the newly industrialising countries (NICs).

\footnotetext{
*This paper is part of a research project dealing with the production of numerically controlled machine tools in the developing countries. The project is financed by the Swedish Agency for Research Cooperation with the Developing Countries whose assistance is gratefully acknowledged.
}

\section{The technology}

Traditionally in batch production, the need for flexibility has meant that standard, hand operated and multipurpose machine tools have been used. As a consequence exceptionally good quality has been difficult to achieve, the level of machine utilisation has been very low due to long change-over times from one product to another, and very skilled people have been needed to set and operate the machine tools. At the beginning of the $1950 \mathrm{~s}$, the first NCMT was developed in which the information needed to produce a particular component was put on a medium (eg a tape) and fed into a numerical control unit. By simply changing the tape, the NCMT could quickly be switched from the production of one type of product to another. A large gain in flexibility has been gained. But the cost and unreliability of the electronic components hindered a wide diffusion of this technology until minicomputers were introduced in 1970. A still more significant change in the technology, which indeed may be looked upon as a great qualitative change as opposed to a change in degree, was the use of microcomputers for the numerical control unit, which were introduced in 1975. The use of microelectronics meant a drastic reduction in price, an increase in reliability, a simplification in programming and the spread of electronics to a range of functions previously not automated, such as tool changing and diagnostics. The technology has now, five years after the introduction of microelectronics, reached maturity and is consequently diffusing rapidly.

\section{The diffusion of NCMTs}

The rapidity of diffusion of NCMTs in the developed countries can be seen from the following trends: in Sweden the share of NCMTs in all machine tools (in value terms) rose from 12.4 per cent in 1974 to $35-40$ per cent in 1979. Numerical control systems are however mainly applied to metal cutting machine tools-as opposed to metal forming ones-and here the share of NCMTs as a proportion of metal cutting machine tools rose from 22.8 per cent in 1974 to 54.1 per cent in 1979. In Japan the share of NCMTs in all metal cutting machine tools rose from 17.4 per cent in 1975 to 35.7 
per cent in 1979. In the case of lathes, one of the most important metal cutting machine tools, the share of numerically controlled lathes was still higher, accounting for 51 per cent in Japan and for around 70 per cent in Sweden and France in 1979. The rapid growth in importance of NC lathes can be appreciated when we note these figures against earlier time periods. In the case of NC lathes their share was only 26.4 per cent in France in 1976, 23.4 per cent in Japan in 1975 and 34.4 per cent in Sweden in 1974.

\section{The direction of technical change}

The rapidity of this diffusion is explained by the following factors:

a) the most important source of productivity increase in savings in labour. For example, a NC lathe substitutes for between two and four conventional lathes. Thus two to four lathe operators are substituted for by one NC lathe operator. In some cases this NC lathe operator can attend two machines, as his function is mainly a supervisory one. Furthermore, as NC lathes contain a computer, various computer guided feeding mechanisms can be attached to the NC machine tools, further reducing the amount of labour time. Moreover, as we shall see, the rate of utilisation of NC machines is higher than for conventional machines, thereby further enhancing the productivity of labour;

b) NCMTs may also save capital. The flexible character of NCMTs means that the capital embodied in stocks and work in progress may be substantially reduced. This is very important as, for example, in the Swedish mechanical engineering sector in 1977 , 30-35 bn kronas were tied up in goods (stocks and work in progress) and only 15-20 bn kronas in machines and buildings. NCMTs also aid in this capital rationalisation process in that they save space. This is an often overlooked source of increase in the productivity of capital. (In fact in 1977, the value of investment in buildings in the Swedish engineeering sector was 84 per cent of the investment in machinery.) In general, the capital saving nature of these aspects offsets the effect of the higher price of the NCMT in relation to standard machine tools, leading to a lower capital cost per unit of output;

c) automatic positioning and control allows for greater precision and uniformity of quality;

d) the existence of flexible manufacturing systems which can cut lead time is playing an increasingly important role in firms' strategies in the face of tough competition.

\section{The skill implications of NCMTs}

There has been a significant reduction in the skills needed to operate the machine tool as well as a reduction in the number of people embodying the skills. An NMCT operator clearly needs some skills, but the maximum time at work and at in-house training courses required for an unskilled person, who has had a technically orientated secondary education, was said by one firm to be 12 months. Other firms suggested a maximum of six months. By contrast, for a qualified operator of a conventional lathe, five years of experience is often mentioned as being necessary merely to acquire proficiency. One firm visited, which had started up with NC lathes, only needed to employ 22 semi-skilled NC operators instead of 44 skilled operators. In another case, 21 NC operators substituted for 63 qualified operators. Hence, for the operation of the machine tools the 'mass' of skills needed has been reduced in a very significant manner. However, NCMTs require a set of other skills which are not important in the case of standard machine tools.

First, in addition to the NC operators, instructors and programmers are needed. Hence, there is a further division of labour. Roughly six to eight NCMTs are served by an instructor and a programmer. These people are often former skilled workers who have joined the ranks of the white collar workers, or people with some technical training, for example technically orientated secondary education.

Second, repair and maintenance has become more complex. This does not apply so much to the mechanical parts, which are in fact simpler in a NCMT since it has less moving parts, but to the electronic parts and the interface. Given that for most users, apart from the larger firms, the electronic part is of a black box character, there is a tendency for the supplier to take over the repair and maintenance work. Usually, there is one engineer employed for 15 installed NCMTs. At the level of the machine tool, the introduction of NC units has increased the skill requirements. However, as the number of machine tools is decreasing due to increases in productivity, the amount of repair and maintenance skills needed to produce a given number of engineering products has not necessarily increased.

All in all, the very dramatic decrease in the number of skills needed at the operational phase is only marginally offset by other skills required in the supervision, programming and repair and maintenance tasks.

\section{Effects on global comparative advantage}

In view of the substantial benefits provided by NCMTs to investors, it is obviously important to determine the impact on users in the developing countries and on global comparative advantage. Contrary to initial expectations there are reasons to believe that the diffusion of NCMTs has the potential to enhance their comparative advantage, especially that of the newly 
industrialising countries (NICs). We now consider these.

Let us sum up the advantage of NCMTs: firstly, firm interviews clearly show that the NCMT is a capital saving technology. The degree of capital saving in relation to conventional technology depends, however, to some extent on the institutional setting. In many developed countries it is difficult, if not impossible, to find skilled workers who are willing to work shifts. This institutional restriction to the full utilisation of all fixed capital, including buildings, probably does not apply to the same extent in the NICs. The skill saving character of NCMTs means that the firms based in a developed country can to some extent overcome this restriction to fuller capital utilisation, and NCMT operators in developed countries were found to be more likely to work two shifts than those firms using conventional technology. As this is probably not an issue in the NICs, we can conclude that NCMTs are slightly more capital saving in relation to conventional machinery in a developed country than in a NIC.

Secondly, NCMTs save on labour in a very dramatic manner. Proportionately more labour is saved than capital. At first sight this might lead us to conclude that the NCMT is a technology which is more appropriate to the developed countries than to the NICs. However, the labour saved is predominantly skilled labour and the labour which remains is mainly unskilled or semi-skilled labour. The total mass of skills required to produce a given set of engineering products has thus been significantly reduced. Thus, proportionately speaking, reduction in skill requirements is of far greater magnitude than the capital or labour saving nature of the NCMTs. This means that the NCMT represents a technical change, the appropriateness of which is a function of the degree of scarcity of skilled labour compared to capital and/or to unskilled labour.

This conclusion is important since it is clear that skilled workers have traditionally been a major source of the developed countries' comparative advantage in the engineering sector. In fact, one study concluded that in the case of $S$ weden, the comparative advantage moved between 1960 and 1970 to branches with a more intensive use of skilled workers [Ohlsson 1976]. ${ }^{1}$ With NCMTs, production of some engineering goods need no longer be placed in economies with an abundance of skilled machine tool operators. As in all other automated production technologies, NCMTs are mobile, and in the future such factors as wage costs and 'workers' discipline' can be expected to be added to other determinants (such as labour skills) of the international location of production.

'Elaboration of data supplied by the Swedish Union of Metalworkers.
To sum up, there are strong reasons for suggesting that NCMTs represent a technical change which is to the benefit of economies with factor endowments of a kind that are usually associated with the NICs. Hence, the direction of technical change favours these economies. To what extent this has actually shifted or reversed the comparative advantage of these NIC economies is, however, more difficult to substantiate. This depends on the exact level of skills in the relevant countries. To answer that question we would need very detailed knowledge of the relative scarcity of the different factors of production in all the relevant countries. However, as a minimum statement, we can safely say that the comparative advantage of the developed countries in metal-cutting has been eroded by NCMTs.

Before drawing too strong a conclusion from this analysis, there are three important considerations to bear in mind:

a) NCMTs only affect production, even if design is being computerised via Computer Aided Design systems [Kaplinsky 1982]. These changes in design technology which appear to be diffusing more rapidly to developed economies, may provide significantly greater benefits, particularly in sectors where product-competitiveness outweighs price-competitiveness.

b) Metal-cutting is only one out of many subprocesses in the engineering industry. Others of importance are metal-forming, casting, heat treatment, joining, assembly, material handling and quality control. In the case of Sweden in 1980, the five largest groups of workers, in terms of hours worked, were: assembly ( 21 per cent), machine tool operators ( 14.6 per cent), material handling (7.6 per cent), welding ( 6.6 per cent) and quality controls (5.9 per cent). Hence, machine tool operators constitute only a small proportion of the total workforce. Furthermore, metal-cutting varied in importance between various products, and the above reasoning applies only to very specific products where metal-cutting accounts for a large proportion of production costs. An example of such a product would be pumps, while electrical motors would be less affected.

c) The present industrial structure of the NICs is such that those branches in which it is profitable to use NCMTs intensively tend to be relatively underdeveloped. Hence, the diffusion of a large number of NCMTs to these economies will take as long as it takes their industrial structure to alter. Of course, the change in comparative advantage through NCMTs may speed up this restructuring process, but there are many other factors at work determining cost differentials. 


\section{The present diffusion of NCMTs to some NICs}

What, then, is the evidence concerning the utilisation of NCMTs in the NICs? There are several ways of measuring the intensity of use of NCMTs. Firstly, one may simply note the number of installed units in the various economies. Thus whereas the US had 54,000 (1978), West Germany 25,000 (1980), the UK 10,000 (1976), and Sweden 4,000 (1980), Argentina only had a total of 325 (1980), Brazil 650 (1979), India 130 (1979) and the Republic of South Korea 1,000 (1980). All in all then, the total stock of NCMTs in the NICs may be around 2,500. This is clearly an insignificant number in relation to the number installed in the developed countries. Furthermore, against the present largescale penetration of NCMTs in the OECD countries, the prospects for the NICs may seem even bleaker. For example, Japan alone installed 8,398 NCMTs in 1979 and the UK doubled its installations of NC lathes between 1978 and 1980.

However, the mere comparison of numbers is not the correct way of answering the question. The number of installed NCMTs must be related to the size of the relevant metal-working sector. Not all branches in the engineering sector use NCMTs. It is only in branches which are characterised by batch production that one may advantageously utilise NCMTs. A study of the diffusion pattern in Sweden revealed that 83 per cent of installed units may be found in nine branches (at four and five digit ISIC level). Hence, the number of installed NCMTs would need to be related to the size of these nine branches in order to get a reasonable idea of the degree of penetration of NCMTs in various economies.

Table 1 relates the number of installed NCMTs to the sales value in these branches in Sweden, Argentina, Brazil and the Republic of South Korea. India has been omitted as it has only 130 installed units. We find that the Republic of South Korea has an intensity in use of NCMTs which is higher than that of Sweden's! Argentina is close to the Swedish figures for 1976 for the case of NC lathes, but has only slightly more than half of Sweden's 1976 intensity for all NCMTs. Brazil (as well as India) lags very far behind. We should note that the data exaggerate Brazil's intensity in use of NCMTs as the sales value is from 1974, whilst for the rest of the countries 1977 sales values have been used.

The difference in the intensity of use of NCMTs in the NICs would appear to reflect the general economic policies of the countries. The exceptionally high Korean figures reflect to some extent Korea's weakness in the relevant branches, but also reflect its heavy emphasis on building up a capital goods sector. Furthermore, Korea has a very short history of skill generation in these branches and should benefit more from the skill saving character of NCMTs than, say, Argentina, which has a long history of capital goods production as well as a long history of immigration of skilled metalworkers. Argentina's lower figure reflects, however, its deep economic crisis after 1977 when the diffusion of NCMTs really started to take off in most other countries. Brazil's exceptionally low figure most probably reflects its policy of import controls, which impedes the diffusion of capital embodying new technology.

In conclusion, of the countries considered, Brazil and India are falling behind in the use of NCMTs. These countries will therefore probably be left behind in productivity growth as well. Korea, on the other hand, is investing heavily in NCMTs and should benefit proportionately more than the advanced countries by this technical change. Argentina falls somewhere in between.

\section{Conclusions}

Looked at in isolation, the NCMT is not a technology which will necessarily lead to an increased technological gap between the developed countries and the NICs. On the contrary, given the right economic policies in the NICs, eg allowing access to NCMTs at world market prices, it is a technology which is at least as suitable to the NICs as to the developed countries. The NCMT has therefore to some extent reduced the comparative advantage of the developed countries in metal-cutting. It is furthermore possible, but not necessary, that it has reversed comparative advantage in favour of the NICs. Hence, the international diffusion of NCMTs may well be associated with an increasing share of these countries in world production and trade in engineering products. In particular, this applies to the Republic of South Korea which has invested heavily in NCMTs as part of its plans to build up a capital goods sector.

There are a few points, though, to be borne in mind:

a) the change in comparative advantage applies only to the production stage and only to products where metal-cutting is of importance;

b) the industrial structure of the NICs needs to be altered in order for them to be able to utilise NCMTs. This applies especially to the Republic of South Korea, but also to Brazil.

Finally, we need to say a few words about the long term trends in engineering technology, as NCMTs represent only one discrete element in the automation process. We noted earlier that the NICs could gain a competitive edge through both lower labour costs and higher utilisation of fixed capital. Automation will affect both these sources of comparative advantage in the future. 
Intensity of use of NCMTs and NC lathes in four countries

\begin{tabular}{llccrr}
\hline & sales value $(\text { bn dollars })^{1}$ & number NCMTs & number NC lathes & $2 / 1$ & $3 / 1$ \\
\hline Argentina & $2.83(1977 / 78)^{2}$ & $325(1980)$ & $215(1980)$ & 114 & 76 \\
Brazil & $8.4(1974)$ & $649(1979)$ & $196(1979)$ & 77 & 23 \\
Korea & $1.55(1977)$ & $1,000(1980)$ & $493(1980)$ & 645 & 318 \\
Sweden & $8.68(1977)$ & $4,000(1979)$ & $1,665(1979)^{2}$ & 460 & $231^{2}$ \\
\hline
\end{tabular}

${ }^{1}$ Sales value refers to 9 branches (ISIC 3811, 3821, 3822, 3823, 3824, 3829, 3831, 38322, 38432). For Argentina ISIC 38322 is excluded due to non-availability of data

${ }^{2}$ Estimated.

Sources: Argentina: sales value is estimated from data supplied by INDEC. The number of NCMTs is estimated from interviews. Brazil: sales value is taken from Censo.Industrial 1974. The number of NCMTs from Stemmer 1981.

Korea: sales value is taken from Report on mining and manufacturing survey 1977. The number of NCMTs is based on The Korean Development Bank 1980, and various statistical yearbooks on foreign trade.

Sweden: sales value is taken from Sind 1979.11. The number of NCMTs and on SOU: 1981:11.

Concerning labour costs, let us go back to the distribution of labour among the different sub processes in the Swedish engineering industry to illustrate my point. In metal-cutting, the proportion of skilled workers is still very high at 51.6 per cent, whilst in, say, material handling it is only 7.6 per cent, and in assembly only 22.5 per cent. This suggests that NCMTs may substitute for skilled workers in metal-cutting so that a NIC could use its relatively low cost semi- or unskilled labour not only for metal-cutting but also for assembly and material handling etc in order to gain a competitive advantage. Underlying this suggestion is a theory of uneven development of automation in the engineering sector. Without attempting to provide full proof, it appears that automation has developed most in the metal-cutting phase, where it substitutes for skilled labour. It has been less developed in assembly and material handling, where it substitutes, to a larger extent, for semi-skilled labour. In the longer run, automation is expected to proceed to these sub processes too. For example, Hitachi hopes, to develop a 'skilled robot' for the assembly of electrical products within five years [Japan Economic Journal 1981]. When these techniques are developed, they will withdraw the basis for cheap labour competition from the NICs. Hence, technical change may in the medium and long term alter the basis for a change in comparative advantage.

With automation also comes an increased possibility to put fixed capital to better use. Already there are techniques developed which feed the NCMTs automatically with parts. The only human intervention needed is to provide the robot or feeding mechanism with a pile of parts. This means that a NCMT can already work for as long as six hours without human intervention.
In the long run, the process of integrating the individual components into the automated factory will pick up speed. Partially automated factories exist, even now. The integration of computer aided design with NCMTs and robots as well as automatic warehouses implies a shift in technology which is of a fundamental nature. Whilst the introduction of a discrete element, say a NCMT or a spray robot, is relatively simple, a system change requires a user competence which is qualitatively different. It is unlikely that NIC-based firms in general will easily follow such a system change. ${ }^{2}$ However, we are not yet at the stage of automated production.

${ }^{2}$ This is of course highly speculative. There are a number of technically progressive firms also in these countries. For example, the Argentinian heavy capital goods firm Pescarmona has not only a very large number of NCMTs but is also installing Computer Aided Design in an effort to break into the world oligopolistic market of heavy electrical equipment.

\section{References}

Japan Economic Journal, 1981

Kaplinsky, R., 1982, The Impact of Electronics on the International Division of Labour: the Illustrative Case of Computer Aided Design, Frances Pinter, London

Ohlsson, L, 1976, Svensk.Verkstadsindustris Internationella Specialisering, IUI, Stockholm

Sind, 1979:11, Industriutvecklingen i Sverige

Stemmer, C. E, 1981, 'Estagio atual do comando numerico no Brasil' in Maquinas \& Ferramentas, May

Sten, H., rapporter fran Sveriges Mekanforbund, 10/8/76, $21 / 10 / 76,8 / 9 / 77$ 